\title{
Aid Ineffectiveness in Sub- Saharan Africa: The Problem of Donor Capacity
}

\section{Diana Conyers and Rob Mellors*}

\section{Introduction}

The reports of the United Nations' Millennium Project recognise that proposals to increase aid could be hampered by lack of capacity in recipient countries, but say very little about the capacity of donors. ${ }^{1}$ This article seeks to demonstrate that donor capacity warrants equal concern. It focuses on subSaharan Africa, which is the region where there has been least progress in achieving the Millennium Development Goals (MDGs) and to which much of the increased aid is thus likely to be channelled. ${ }^{2}$

There is substantial evidence to suggest that, while the problems of capacity in African countries are great and cannot be ignored, the manner in which aid is delivered is just as much a problem. Van de Walle and Johnston (1996), summarising a study of aid effectiveness in seven African countries, show how aid often weakens rather than strengthens local institutions. Similarly, Lancaster (1999: 3-4) concludes from a study of the performance of eight major donors in Africa that, "contrary to widely held views ... the main problem is the lack of capacity on the part of aid agencies to undertake the kind of interventions they have attempted'. These agencies, she says, 'have often lacked the technical experience, local knowledge, staff, and appropriate processes to manage such projects and programs effectively'. Bräutigam and Knack (2004) conclude from an analysis of data for 32 African countries, that aid has a negative impact on the quality of governance and that this is due in large part to the manner in which it is delivered.

As the quotation from Lancaster implies, the question of whether donors have the capacity to deliver increased quantities of aid effectively is not just about whether sufficient financial and manpower resources can be mobilised. As with recipient governments, it is also necessary to ask whether donor agencies have the necessary organisational structures and procedures, knowledge and skills, and attitudes. In our view, the answer to this question is that they do not. We shall demonstrate this by examining five aspects of the design and implementation of donor-funded interventions that we consider particularly critical in determining aid effectiveness, namely:

1. The extent of ownership of, and therefore commitment to, the intervention in the recipient country

2. The appropriateness of the intervention to the environment of the recipient country

3. The organisational structures and procedures through which interventions are implemented and monitored

4. The degree of flexibility in programme design and implementation

5. The quality of technical expertise within the donor agency.

We shall support our argument with references to the literature and with examples of both good and bad practice drawn from our own experience in sub-Saharan Africa over the last three decades.

\section{Local ownership and commitment}

Ownership and commitment go hand in hand. We use the term "ownership" to mean that the recipient has not merely agreed to an externally supported intervention, but is genuinely committed to it. Van 
de Walle and Johnston (1996: 54) say that 'recipient governments can be said to "own" an aid activity when they believe that it empowers them and serves their interest', while Unsworth (2001: 11) maintains that "local ownership" must mean "local leadership". The reasons why ownership and commitment are so important are well known and documented. As van de Walle and Johnston (1996: 54) explain, 'from a sense of ownership flows the willingness to commit real resources to ensure the activity's success, to solve problems that emerge during implementation, and to sustain the activity after the withdrawal of aid'. However, the conclusion from their study is that, although 'the importance of ownership is widely acknowledged [by donors] as essential to the success and sustainability of development efforts', in reality they 'still tend to dominate the project cycle and pay inadequate attention to the preferences of the government or project beneficiaries' (van de Walle and Johnston 1996: 54-5).

Our own experience supports this conclusion. We have encountered some externally supported interventions with a high degree of local ownership. Examples include:

- Uganda's Poverty Eradication Action Programme, widely regarded as one of the most successful attempts to utilise debt-relief funds for poverty alleviation (Amis 2002)

- Zimbabwe's local government capacity-building programme, which received external support for 12 years and was only brought to a halt by the deteriorating political situation in Zimbabwe (Mellors et al. 2002)

- Ethiopia's current public service delivery capacitybuilding programmes

- An NGO-funded community development initiative in the Binga District of Zimbabwe, which demonstrates the importance of ownership at community as well as national level (Conyers and Cumanzala 2004).

In all these cases, the recipient organisation identified the need for the intervention and played the lead role in its design and implementation; external aid was merely a means of enabling it to achieve its objective.

However, we have also come across many cases where there has not been sufficient ownership or commitment and where the blame for this must rest in large part with the donor. For example, in Nigeria, the Department for International Development's (DFID) attempts to fund state-level public sector reform programmes have had very little success because of lack of ownership and commitment by the state governments. And in Uganda some donors have played a highly proactive role in the design of local government support programmes, ${ }^{3}$ and there is a risk of the same thing happening with similar programmes currently being designed in South Sudan.

Why do donors persist in supporting interventions that lack the necessary ownership and commitment? There are two main reasons. One is insufficient understanding of the policy environment in the recipient country. For example, DFID's decision to fund state-level reforms in Nigeria was based on the assumption that the election of a democratic government was in itself enough to provide a fertile environment for public sector reform - an assumption that they later found to be false (Heymans and Pycroft 2003). We shall return to this issue later in the article. The other, and usually more important, reason is the pressure on donor agencies to spend money. This pressure stems from a combination of factors: spending targets set by the donor government (often for political rather than "developmental" reasons), competition between donors and the need for individual agency staff to justify their own existence.

\section{Appropriate interventions}

Africa's history is littered with examples of inappropriate development interventions introduced by "outsiders" - from the British colonial government's notorious groundnut scheme in the 1950s to the World Bank's structural adjustment programmes in the 1980s. Other documented examples include the 'training and visit' agricultural extension system (Hulme 1992), public sector reform programmes (Polidano 2001), and "new" public management (Manning 2001). An example of inappropriate "new" public management practices is the performance appraisal system used in Uganda's World Bank-funded Local Government Development Programme, which encourages "upward" and "external" rather than "downward" and "internal" accountability and requires so much organisation and financial support that there is no way it will be sustained when external funding and pressure - is removed (DIP 2002). ${ }^{4}$ 
Interventions like this fail for two reasons. First, they are incompatible with the local physical, socioeconomic and/or political environment. Thus, Manning (2001: 302-3) explains how "new" public management reforms have tended to fail for the same reasons as the "old" ones did - for example, lack of skills and resources, corruption and undue political influence. Equally important, however, is the fact that they are imposed from outside rather than generated locally. This relates to the earlier point about ownership. As Bräutigam and Knack (2004: 261-2) point out, the process of analysing problems and identifying appropriate solutions is an essential component of the concept of "ownership". It is also the only way in which Africans will find sustainable solutions to their development problems.

This point has long been recognised. For example, Dumont (1962), in his book False Start in Africa, highlighted the need for 'local' solutions to 'local' problems while, in another classic text, Schumacher (1973) emphasised the importance of self-learning. More recently, it has been increasingly emphasised by African political leaders and intellectuals. It is reflected in attempts to find an African alternative to structural adjustment in the late 1990s (Sogge 2002: 68), in the formulation of the New Partnership for African Development (NEPAD), and in the African Union's insistence that it take the lead in resolving conflicts in areas such as the Sudan. ${ }^{5}$

Why then do donors continue to introduce inappropriate solutions? Inadequate understanding of the environment in the recipient country is again part of the problem. However, there are two other reasons. First, many donor policy documents including the reports of the Millennium Project give the impression that the answers to Africa's development problems are known. ${ }^{6}$ In reality, however, most of the problems are complex and there are no easy or obvious solutions; if there were, the MDGs would have been achieved in the previous millennium. Second, current aid discourse, like "new" public management discourse in general (Hood 1991, 1998), is characterised by the constant "invention" of new "fashions" - that is, new solutions or approaches, which displace the previous ones before the latter have been properly tested. Recent changes in DFID's governance policy are a case in point. ${ }^{7}$ More often than not, these fashions are not really new; they are merely new (and often more complicated) ways of expressing old wisdom. Moreover, there is a mistaken tendency to assume that they are universally applicable - the "one size fits all" approach.

\section{Organisational structures and procedures}

One of the most widely acknowledged problems of donor-funded interventions is that donors have their own procedures for designing, approving, monitoring and evaluating the activities that they fund, procedures that inevitably differ from those of recipient organisations. Officials in the recipient organisations thus have to expend much time and effort learning and following the required procedures - time and effort that would much better be spent on strengthening internal management systems. ${ }^{8}$ Since each donor has its own set of procedures, this problem underlies much of the wider problem of donor coordination. Bräutigam and Knack report (2004: 261) that in Ghana 'senior officials each spent as much as 44 weeks a year facilitating or participating in donor supervision missions, time they were unable to devote to their ministries' own priorities', while Amis (2002) reported a similar situation in Uganda. Our own experiences in Uganda, and also recently in South Sudan, confirm the problem.

In many cases, donors also require the establishment of special organisational units to implement "their" interventions. The impact of these "parallel structures" is even more damaging, since they not only divert time and effort from strengthening existing structures but actually undermine them. The special units offer higher salaries and better working conditions than the existing organisations, and so "poach" the latter's most capable staff, thereby reducing organisational calibre and the morale of remaining staff. This results in the transfer of more responsibilities to the special units, thus creating a vicious circle of institutional degradation. Integrated rural development programmes (Conyers et al. 1988) and social funds (de Haan 2002) are classic examples of donor-funded activities operated through parallel structures.

Ironically, such structures are most common in countries where government institutions are weakest. They are justified as being the only way of delivering complex and/or much-needed public services in such an environment, but the result is that the weak institutions become even weaker and 
aid dependency increases rather than decreases. Uganda is a case in point. Parallel structures were used to spend the large amounts of aid introduced after Museveni came to power in 1986, because the administrative infrastructure had been almost totally destroyed by years of civil war. The results of this strategy are still evident today. Many government departments exist in little more than name, since the most important activities are implemented through special, donor-subsidised units. The problem has now been recognised by both donors and the Uganda Government (see Kitabire, this IDS Bulletin), and steps are being taken to do what should have been done 20 years ago - develop the capacity of departmental structures and systems. Bräutigam and Knack (2004: 262) describe a similar situation in Mali.

There are some relatively positive experiences from which lessons might be drawn. For example, in Zambia, Zimbabwe and Ethiopia we have helped to establish local government capacity-building projects that operate through, rather than in parallel to, existing institutions and involve a considerable degree of donor coordination (Mellors et al. 2002; Zimbabwe 1998). In Zimbabwe we also assisted the government to persuade the World Bank to allow a Bank-funded social fund (the Zimbabwe Community Action Project) to be implemented through local governments, using the experience gained from the local government capacity-building programme. However, even in these cases, donors continued to require some special management procedures, and sometimes also special units within the implementing government agency. Furthermore, our experience suggests that the coordination of donor efforts can be a mixed blessing because it is often the donors rather than the recipient governments that do the coordinating and this strengthens the influence of the donors vis-à-vis the governments. Ugandas Donor Decentralisation Coordination Committee is a good example (DIP 2002).

The recent trend among many donors to move from individual projects to sector-wide approaches (SWAPs), poverty reduction support programmes (PRSPs) and, most recently, general budget support, should in theory reduce the problem. However, experience suggests that this may merely mean that one set of structures and procedures is replaced by another, equally complex and time-consuming set. Berg (1997) argues that sectoral programmes actually require more complex management systems than individual projects, while Bräutigam and Knack (2004: 278) confirm our own experience of PRSPs, notably that:

the extensive conditions required for poor countries to qualify for debt relief mirror the aid system itself, with high transaction costs and extensive use of foreign consultants to develop the required poverty reduction programs and plans.

Once again one must ask why, when these problems are so widespread and well known, they have persisted so long. The main reason is that most donor agencies are large organisations that operate in many countries and are accountable to their own governments or boards of directors; they are therefore bound by their own operational procedures and by the need to account for the money they spend. However, this is often reinforced by lack of trust in the capacity or commitment of the recipient organisation.

\section{Flexibility of programme design and implementation}

The implementation of development interventions in Africa is characterised by uncertainty. This uncertainty often stems not only from the external environment but also from the nature of the interventions themselves, which frequently involve the application of ideas or approaches that have not been fully tested in the present environment. This suggests the need for a flexible "process" approach to programme design and implementation, rather than a rigid "blueprint" approach. A process approach allows a project or programme to evolve in a manner and at a speed that is consistent with the local environment and for all those involved in its implementation to learn as they go along and adapt their activities accordingly (see also Eyben, this IDS Bulletin).

The need for a process approach has long been recognised. In the 1980s it featured prominently in the development literature (Korten 1980; Lecomte 1984; Rondinelli 1983) and was reflected in a number of development projects. We were personally involved in transforming a DFID-funded integrated rural development project in Zambia from a "blueprint" to a "process" approach around that time. This provided a model for similar transformations of other Zambian Integrated Rural 
Development Programmes (IRDPs) and for the design of Zimbabwe's local government capacitybuilding programme (Conyers et al. 1988; Mellors et al. 2002). Many NGOs also adopt a process approach when funding small, community-based projects, where (as Korten emphasised) flexibility is particularly appropriate.

However, such projects are the exception rather than the rule. The World Bank is among the worst offenders. The process of designing and implementing a Bank-funded project resembles an industrial production line. There are a series of mandatory steps that have to be gone through in a specific sequence and, as far as possible, at a predetermined pace - irrespective of the nature of the project or the environment. Once the recipient government gets on this production line, it is very difficult to get off it, or even to modify or delay the "production" process. In fact, the only modification the Bank is likely to encourage is to "fast-track" the process, a move that frequently results in projects being implemented without sufficient preparation and/or the necessary degree of recipient ownership and commitment. As Polidano (2001: 6) says, 'forcing the pace can lead to disaster. One has to proceed slowly, pace by pace, watching one's step very carefully indeed'.

The problem, once again, is that donor agencies are driven by their own motives and constraints. They need a blueprint plan that spells out how, when and where the money will be spent in order to access the money and provide a basis from which to monitor implementation performance. And they need to move projects along the production line as quickly as possible in order to meet spending targets and justify the continued existence of the sections and individuals involved.

\section{Quality of technical expertise}

Donors require technical expertise at various stages in the aid "delivery" process: assessing the scope for intervention; assisting the recipient organisation in detailed project design; providing any technical support required during implementation; and monitoring and evaluating progress and impact. In order to undertake these tasks efficiently and effectively, they require an in-depth knowledge of both the country concerned and appropriate development theory, and they must be able to access individuals with appropriate skills as and when required. We have already noted that lack of such expertise contributes to other capacity problems.

Our own experience suggests that the quality of donor expertise in sub-Saharan Africa has deteriorated over the last 25 years. Although the situation varies from donor to donor, there appears on the whole to be less in-depth understanding of Africa's development problems, less ability to provide expertise as and when required and less "organisational learning".

There are several possible reasons for this. One is the increasing size, centralisation and "bureaucratisation" of many aid agencies (Lancaster 1999: 223-6), which results in staff spending more time meeting the internal bureaucratic requirements of the organisation than learning about the environment of the countries where they work. Another is the constant pressure for change in such agencies, including changes in organisational structure, in policies and priorities and the movement of staff. This phenomenon, which is related to the problems of "new" public management discussed previously, makes it difficult for both individuals and the organisation as a whole to develop in-depth knowledge and understanding. A third factor is what Dichter (2003: 226-38) calls the 'professionalisation of development'. According to Dichter, today's development professionals differ from their predecessors: they tend to be specialists rather than generalists, to regard their work as a profession rather than a vocation, and to measure their performance in terms of career development and peer recognition rather than achievements on the ground. Although he probably exaggerates the differences between the two groups, he makes a valid point.

In our view, however, the most important reason for the decline in the quality of technical expertise, and one that has received very little attention in the literature, is that aid agencies now contract out so much of their work to private consultants. Until the mid-1980s, agencies such as DFID (then the Overseas Development Administration, ODA) used in-house staff for most policy formulation and project identification, design and management activities. Moreover, if technical assistance was needed for project implementation, personnel were employed directly, usually from a pool of experienced professionals who were already known to the organisation. Consultants were only used to fill specialised gaps or undertake activities like evaluation, which require an independent view. But today, consultants are employed to do anything, 
from developing policy and identifying possible areas of intervention to detailed project design and the actual management of development projects.

This practice, which is characteristic not just of aid management but of current public management practice in general, creates two major problems:

1. Knowledge and expertise is no longer accumulated in the agencies themselves, but in the consultants. There is a vast reservoir of knowledge among consultants - and in their countless reports. However, because the consultants are constantly moving from agency to agency and job to job and their reports are not "internalised" within the agency, this knowledge is not used to influence aid activities in a consistent or coherent manner.

2. The procedures by which consultants are hired, especially the prolonged process of competitive bidding, makes it very difficult to get the right person in the right place at the right time. The system might work if there was a pool of appropriately qualified consultants ready and waiting to go whenever and wherever they were needed; but consultants cannot afford to sit around waiting for work in this way. ${ }^{9}$

Constraints on space prevent a more detailed discussion of this issue here, but in our view it is of critical importance in determining aid effectiveness.

\section{Conclusions}

It is evident from the literature and our own experience that, in order to increase aid effectiveness in Africa, there must be changes in donor structures

\section{Notes}

* We would like to thank David Pudsey for the contribution he has made to our thinking over the years and his comments on this article.

1. For example, the Overview of its 2005 report, Investing in Development, has a short section on 'Key measures to improve aid delivery', which focuses on the content of aid programmes; it does not address any of the issues in this article.

2. For a detailed analysis of the lack of progress in subSaharan Africa, see Sahn and Stifel (2003).

3. In one case a donor persisted in designing a support project when there was only lukewarm support from the and procedures, knowledge and skills and attitudes. It is essential that donors:

- support only those interventions that demonstrate genuine recipient ownership and commitment;

- promote interventions that are appropriate to the local environment;

- work through the recipient country's existing management structures and procedures rather than their own;

- adopt a flexible "process" approach; and

- enhance their technical capacity to do the above by strengthening in-house knowledge and expertise and reducing the use of consultants.

However, it is equally evident that there are major obstacles to such changes. Aid agencies are constrained by the organisational structures and procedures of their own governments (which in turn reflect global trends in public management practice), by the need to be accountable to these governments - and ultimately to the taxpayers, and by the non-humanitarian motives for providing aid. Moreover, and probably most important, there are many people with vested interests in the existing systems - including not only aid officials and consultants from the donor countries but also many people in recipient countries who benefit personally from the current ineffective practices.

Are we prepared to defy these constraints and make the necessary changes in order to meet Africa's very real humanitarian needs? If we are not, the prospects are bleak. Pushing more money through a defective system is wasteful and could do more harm than good.

government, while in another the government was forced to agree to amend draft local government tax legislation as a pre-condition for proceeding with negotiations for a World Bank-funded programme.

4. The appraisal system provides the basis for the allocation of development funds to the country's local authorities. The performance of the approximately 950 local authorities is appraised against a complex set of up to 80 criteria.

5. There are indications that it will also play a prominent role in the forthcoming report of the Commission for Africa.

6. The World Bank's annual World Development Reports are another prime example. 
7. In the space of a few years, the emphasis has switched from "organisational development" to "institutional development", and then to "drivers of change" - which appears now also to have been replaced, but with what is not yet clear.

8. Of particular importance is the development of financial systems, since these constitute the basis for planning and monitoring government activity and thus creating efficient

\section{References}

Amis, P., 2002, 'Uganda: a country case study', paper prepared for the Organisation for Economic Cooperation and Development (OECD) DAC Task Force on Donor Practices

Berg, E., 1997, 'Dilemmas in donor aid strategies', Perspectives on Aid and Development, Washington, DC: Overseas Development Council: Policy Essay No 22, Chapter 3

Bräutigam, D.A. and Knack, S., 2004, 'Foreign aid, institutions, and governance in sub-Saharan Africa', Economic Development and Cultural Change, Vol 52: 255-85

Conyers, D. and Cumanzala, F., 2004, 'Community empowerment and democracy in Zimbabwe: a case study from Binga District', Social Policy and Administration, Vol 38: 383-98

Conyers, D., Mosely, P. and Warren, D.M. (eds), 1988, 'Integrated rural development: lessons of experience', Manchester Papers on Development, Vol 4 No 1 (special issue)

de Haan, A., Holland, J. and Kanji, N., 2002, 'Social funds: an effective instrument to support local action for poverty reduction?', Journal of International Development 14: 643-52

DIP (Development in Practice), 2002, 'Formulation of a programme in support of decentralization in Uganda (9th EDF)', report prepared for Government of Uganda and European Commission

Dichter, T.W., 2003, Despite Good Intentions: Why Development Assistance to the Third World Has Failed, Amherst: University of Massachusetts Press Dumont, R., 1962, False Start in Africa, London: Andre Deutsch

Heymans, C. and Pycroft, C., 2003, Drivers of Change in Nigeria: A Preliminary Overview, Abuja: Department for International Development (DFID) Nigeria

Hood, C., 1998, The Art of the State, Oxford: Oxford University Press: Chapter 1

Hood, C., 1991, 'A public management for all seasons?', Public Administration, Vol 69: 3-19 and accountable governments. However, it is in the financial sphere that donors are most likely to require special procedures.

9. The problem is greatest with international consultants, since they work in many different countries. In the case of local consultants, it is somewhat easier to develop a pool of expertise.

Hulme, D., 1992, 'Enhancing organisational effectiveness in developing countries: the "training and visit" system revisited', Public Administration and Development, Vol 12: 433-45

Korten, D., 1980, 'Community organization and rural development: a learning process approach', Public Administration Review, Vol 40 No 5: 480-511

Lancaster, C., 1999, Aid to Africa, Chicago: Chicago University Press

Lecomte, B., 1984, Project Aid: Limitations and Alternatives, Paris: Organisation for Economic Cooperation and Development

Manning, N., 2001, 'The legacy of the New Public Management in developing countries', International Review of Administrative Sciences, Vol 67: 297-312

Mellors, D.R. et al., 2002, Capacity Building for Decentralised Local Governance in Zimbabwe: Lessons from PDSP and RDCCBP, Nottingham

Polidano, C., 2001, 'Why civil service reforms fail', Public Policy and Management Working Paper 16, Manchester: University of Manchester, Institute of Development Policy and Management

Rondinelli, D., 1983, Development Projects as Policy Experiments, London: Methuen

Sahn, D.E. and Stifel, D.C., 2003, 'Progress towards the Millennium Development Goals in Africa', World Development, Vol 31: 23-52

Schumacher, E.F., 1973, Small is Beautiful, London: Abacus

Sogge, D., 2002, Give and Take: What's the Matter with Foreign Aid?, London: Zed Books

Unsworth, S., 2001, Understanding Pro-Poor Change: A Discussion Paper, London: Department for International Development (DFID)

van de Walle, N. and Johnston, T., 1996, Improving Aid to Africa, Washington, DC: Johns Hopkins Press

Zimbabwe, 1998, Sustainable Rural Development, Harare: Development in Practice/CapacityBuilding Coordinating Committee 